\title{
Hepatitis B surface antigen prevalence among 12 393 rural women of childbearing age in Hainan Province, China: a cross-sectional study
}

\author{
Yu Zhang ${ }^{1}$, Weiming Fang ${ }^{1}$, Lichun Fan ${ }^{1,2}$, Xiaohui Gao ${ }^{1}$, Yan Guo', Wenming Huang ${ }^{2}$ and Yukai Du*
}

\begin{abstract}
Background: Hepatitis B virus (HBV) infection is highly endemic in China and it threats human health seriously. The hepatitis B surface antigen ( $\mathrm{HBsAg}$ ) prevalence among women of childbearing age plays an important role in mother to child transmission of HBV, as 30\% 50\% of chronic carriers can be attributed to maternal-infantile transmission. However, there are few studies which have reported on the prevalence of HBsAg among women of childbearing age in China. This study aimed to determine the prevalence of HBsAg and its associated risk factors among rural women of childbearing age in Hainan, which is the highest hepatitis B virus endemic province in China.

Methods: A cross-sectional, population-based study, which included 12393 rural women aged $15 \sim 49$ years, enrolled by a multistage stratified cluster sampling, was carried out in Hainan province, China, from November 2007 to December 2008. Blood samples were obtained from each study participant, and screened for HBsAg.

Results: The overall HBsAg prevalence of childbearing age women was 9.51\%. Risk factors for HBsAg positivity among rural women were: lower education level $(O R=1.206)$, lower family monthly income $(O R=1.233)$, having an HBsAg-positive family member ( $\mathrm{OR}=1.300)$, without an immunization history $(\mathrm{OR}=1.243)$, tattooing $(\mathrm{OR}=1.190)$, body piercing ( $O R=1.293)$, vaginoscopy history $(O R=1.103)$ and history of induced abortion $(O R=1.142)$.

Conclusions: There is a high HBsAg seroprevalence rate among rural women of childbearing age in Hainan province. Hence, it is necessary to take preventive measures to reduce the seroprevalence of HBsAg and to control its associated risk factors.
\end{abstract}

Keywords: China, Women of childbearing age, Hepatitis B surface antigen, Seroprevalence, Risk factors

\section{Background}

Hepatitis B virus (HBV) infection is an important public health problem worldwide, more than two billion people (one third of the world's population) have been infected with HBV, and between 350 and 400 million people have chronic liver infections with the presence of hepatitis $\mathrm{B}$ surface antigen (HBsAg) [1-3]. A range of $25 \% \sim 40 \%$ of patients with chronic HBV infection eventually develops the complications of cirrhosis and/or hepatocellular carcinoma (HCC) [4]. Globally, the prevalence of chronic HBV infection is classified into three groups: high

\footnotetext{
* Correspondence: duyukai100@yahoo.com.cn

'Department of Maternal and Child Health, School of Public Health, Tongji Medical College, Huazhong University of Science and Technology, 13th Hangkong Road, Wuhan, P.R, China

Full list of author information is available at the end of the article
}

prevalence $(>8 \%)$, intermediate prevalence $(2 \% \sim 8 \%)$ and low prevalence $(<2 \%)[2,5]$. China is classified as having a high endemicity of hepatitis $B$ virus $[1,6]$. Furthermore, China is now the only country in Asia that remains in high HBV endemicity, with $7 \pm 20 \%$ prevalence of $\mathrm{HBsAg}$ positivity [6]. According to a national survey conducted in 1992, the overall prevalence of HBsAg in the Chinese population was $9.75 \%$, and the HBV infection rate was as high as $50.04 \%$ [7], which were much higher than many other countries.

The first serologic marker of HBV infection is HBsAg, which can be detected from 2 to 12 weeks after infection with HBV. The presence of HBsAg indicates that the person is potentially infectious [8]. HBsAg positive mothers are believed to account not only for mother to
C Biomed Central

(c) 2013 Zhang et al.; licensee BioMed Central Ltd. This is an Open Access article distributed under the terms of the Creative Commons Attribution License (http://creativecommons.org/licenses/by/2.0), which permits unrestricted use, distribution, and reproduction in any medium, provided the original work is properly cited. 
child transmission at birth but also for the intrafamilial horizontal transmission of HBV during infancy and early childhood [9]. Vertical transmission is the major cause of HBV transmission in China. There are more than 130 million chronic carriers of HBV in China, 30\% 50\% of which are attributed to maternal-infantile transmission [10]. Children born to HBsAg positive mothers have a significantly higher risk of becoming $\mathrm{HBsAg}$ positivity than those born to HBsAg negative mothers [11]. The prevalence of HBsAg among women of childbearing age plays a very important role in the transmission and prevalence of HBV. Although some studies have reported on the seroprevalence of HBsAg and its related risk factors among the general population [12,13], blood donors [14,15], pregnant women $[16,17]$ and health care workers [18] in the past few years, few studies have focused on women of childbearing age ( $15 \sim 49$ years).

Hainan province is the youngest province and biggest special economic zone in China, located in the southernmost part of China and surrounded by the sea. The results of the Chinese national HBV seroprevalence survey in 1992 has shown that Hainan was a highly hepatitis $B$ virus endemic region, with the prevalence of HBV and HBsAg was $84.77 \%$ and $16.54 \%$, respectively; both of them were much higher than other provinces in China [7]. This high prevalence of HBV infection seriously hindered the development of economy and the quality of people's health in Hainan. The aim of present study is to explore the seroprevalence of HBsAg and its related risk factors among rural women of childbearing age in Hainan.

\section{Results}

This study included 12393 rural women of childbearing age with an age range of 15 to 49 years and a mean age of $32.25 \pm 7.68$ years, while the median age of 34 years. All of their serum samples were tested for the presence of HBsAg. A total of 1179 women tested positive for HBsAg. The prevalence of $\mathrm{HBsAg}$ positivity in this population was $9.51 \%$ (95\% CI: $8.99 \sim 10.02$ ). The mean age of HBsAg positive women was $35.39 \pm 7.48$ years and their median age was 35 years.

\section{HBsAg seroprevalence with different socio-demographic characteristics}

Table 1 presents the seroprevalence of HBsAg with socio-demographic characteristics of the study samples. HBsAg carrier rate was significantly associated with age $(p=0.001)$. The prevalence of HBsAg was $11.37 \%$ in the age group of $30 \sim 34$ years, $10.51 \%$ in $25 \sim 29$ years old, $10.32 \%$ in $20 \sim 24$ years old, and $7.35 \%$ in $45 \sim 49$ years old. Rural women of Li ethnic minority in Hainan had a higher level of HBsAg positivity than those of Han and other ethnic minorities $(p=0.001)$. HBsAg positivity was seen to be higher among childbearing age women who were divorced or widowed (10.25\%, 95\% CI: 8.29 12.21) than single and married women, although there was no significant difference among different married status $(p=0.393)$. Education level had a statistically significant effect on HBsAg positivity among women of childbearing age $(p=0.002)$. Rural women of childbearing age who were housekeepers had a higher HBsAg positivity than whose who were employed $(p=0.010)$.

The prevalence of HBsAg was higher among women with lower family income ( $<1000 \mathrm{RMB} /$ month) than in the group with higher family monthly income $(p=0.013)$. In this study, $58.69 \%$ of women were nulliparous; the prevalence of $\mathrm{HBsAg}$ among nulliparous women (10.86\%, 95\% CI: $10.14 \sim 11.58)$ was significantly lower than among multigravidae $(12.17 \%, 95 \%$ CI: 11.27 13.07) $(p<0.001)$. When we compared the residential status and HBsAg positivity, the results showed that 432 (10.15\%, 95\% CI: 9.24 11.06) rural women who came from the west of Hainan province tested positive for HBsAg, significantly higher than those who came from the centre and east of Hainan $(p=0.011)$.

\section{Risk factors of HBsAg seroprevalence among women of childbearing age}

Univariate analysis by Chi-square test was carried out to identify factors associated with the prevalence of HBsAg. The independent variables included education level, family monthly income, have an HBsAg-positive family member, tattooing, body piercing, immunization history, history of dental surgery, history of surgery, transfusion history, vaginoscopy history, endoscopy history and history of induced abortion. As results showed in Table 2, there was no association between HBsAg prevalence and history of dental surgery, history of surgery, transfusion history and endoscopy history $(p>0.05)$, but the rest of the variables increased risk of HBsAg. Rural women who had junior high school or lower education level had a higher prevalence of HBsAg than with a senior high school or higher education level $(\mathrm{OR}=1.206,95 \% \mathrm{CI}$ : $1.066 \sim 1.365)$. The HBsAg infection risk among women whose family monthly income were lower than two thousand RMB was higher than those with family income above two thousand $\mathrm{RMB}(\mathrm{OR}=1.233,95 \% \mathrm{CI}$ : 1.075 1.416). Having an HBsAg-positive family member was also a risk factor of HBsAg infection (OR=1.300. $95 \%$ CI: $1.075 \sim 1.416)$. Individuals who reported no history of immunization had a higher prevalence of HBsAg than those with a history of immunization $(\mathrm{OR}=1.243$, $95 \%$ CI: $1.096 \sim 1.410)$. There was a significant relationship between tattooing and body piercing with $\mathrm{HBsAg}$ seroprevalence $(\mathrm{OR}=1.190,95 \% \mathrm{CI}: 1.005 \sim 1.410$; $\mathrm{OR}=1.293,95 \%$ CI: $1.110 \sim 1.506$, respectively). Furthermore, the HBsAg prevalence among women who had 
ever had a vaginoscopy or history of induced abortion were higher than those women who never had such experiences $(\mathrm{OR}=1.190,95 \% \mathrm{CI}: 1.005 \sim 1.410$; $\mathrm{OR}=1.293$, $95 \%$ CI: $1.110 \sim 1.506$, respectively).

\section{Discussion}

Hepatitis B has been a serious public health problem in Hainan for a long time. In 1992, the Chinese national HBV seroprevalence survey found that the HBsAg seroprevalence of the population in Hainan was 16.54\%, ranking first in China [7]. The seroprevalence level of HBsAg of $9.51 \%$ in this study of the childbearing age women in Hainan is higher than the $7.18 \%$ found among the overall population of China [19]; it is also higher than those women of childbearing age in Jiangsu province, China (6.71\%) [17], pregnant women in Catalonia, Spain (1.2\%) [16] and in Greece (1.16\%) [20]; but lower than women of childbearing age in Madagascar (13.6\%) [21]. Overall, the high positive rate of HBsAg among rural women of childbearing age in Hainan highlights the need for public health workers and government to come up with preventive measures of reducing the prevalence of HBsAg among women of childbearing age.

This study showed that HBsAg carrier rate was significantly related with age of the rural women. The highest prevalence of HBsAg is in the age group of $30 \sim 34$ years, followed by the age group of $25 \sim 29$ and 20 24 years, which are at the peak period of pregnancy. Similar results were found in other studies conducted in Turkey [22], Lorestan, West of Iran [23], Nicobarese tribe [24] and Mexico which was a country of low endemicity for HBV [25]. Mother to child transmission is an important transmission route for HBV; $30 \% \sim 50 \%$ of chronic carriers of HBV in China can be attributed to maternal-infantile transmission [10]. Furthermore, Ranger-Rogez S [26] pointed out that if the mother was $\mathrm{HBsAg}$ positive, plus HBeAg and DNA positive, the risk for the neonate to be infected was about $90 \%$, and this child would become a chronic carrier in $80 \%$ $90 \%$ case. The prevention and control of HBV infection among women of childbearing age should therefore, be a priority of public health intervention in order to reduce the transmission of HBV from mother to child.

Our study found that the HBsAg positivity rate among women of $\mathrm{Li}$ ethnic group was higher than $\mathrm{Han}$ and other ethnic groups. Li people are the largest ethnic minorities in Hainan, with $14.73 \%$ of all Hainan population. $\mathrm{Li}$ people are the aboriginal peoples of Hainan, with a history of thousands of years. There are 1.25 million people of $\mathrm{Li}$ ethnic in China, and 1.11 million of them are from Hainan. However, epidemiological data on the different prevalence rate of HBsAg between $\mathrm{Li}$ women and women from the other ethnic background in China are limited, only a few studies have been conducted in counties and cities of Hainan province [27,28]; and their results are consistent with this study. As regards to few epidemiological studies conducted on the subject among $\mathrm{Li}$ people, the cause of high prevalence rate of HBsAg among this group is still unknown. Despite this, there are two possible reasons. Firstly, Li people have a different dietary habit and lifestyle from Han people, for instance, communal eating and living together is commonly practiced among Li people [29]. An experiment done by Bancroft WH et al. [30], demonstrated that human saliva can serve as a vehicle for the transmission of hepatitis B virus. Another study has also shown that HBV may occur in households with a persistent carrier probably via saliva or open wounds, although it is less efficient than sexual or perinatal transmission [31]. Secondly, there may be HBV susceptibility genes among Li people; for ethnicity might play a role in the different prevalence rates of the HBsAg [32]. This calls for molecular epidemiological studies to verify this notion.

In this study, the HBsAg prevalence was strongly correlated with low education level and low family income. The prevalence of HBsAg in women with junior high or lower education level was higher than in those with higher level, which is consistent with previous studies conducted in general population samples [12,23]. People with a higher level of education tend to efficiently utilize health services like vaccination, health education, high quality dentistry services, etc. The prevalence of HBsAg in individuals with a lower family monthly income $(<2000 R M B)$ was significantly higher than those with a higher income level ( $\geq 2000 \mathrm{RMB})$. This result is similar to other studies' reported that positive HBsAg status was less likely to occur among people with high socioeconomic status compared to those with low or middle socioeconomic status [32,33]. Poor and crowded living conditions, which are common in rural areas, can facilitate horizontal transmission between siblings, especially with a high rate of $\mathrm{HBsAg}$ carriers, as described elsewhere [31]. The finding of our study indicated that HBsAg positivity rate among rural women of childbearing age in Hainan province was geographically influenced. The positivity rate tended to be higher in the western region followed by the central and the east region, which was opposite to the economic level distribution pattern [34]. This finding agrees with the finding in our study, that economic status was a major risk factor of HBsAg prevalence.

Another most common factor observed was having an HBsAg-positive family member. Previous researches found similar results deduced from the general population $[13,29,35]$. Our results demonstrated that no previous history of vaccination significantly increased risk of $\mathrm{HBsAg}$ infection. This illustrates the need and importance of 
expanding and re-intensifying immunization program with extension to adults.

Rural women of childbearing age with tattoo and body piercing were significantly higher than those with no tattoo or body piercing. In a study by Zhang et al. [36] in Canada, tattooing and body piercing increased the risk of HBsAg significantly. In Mexico with low endemicity for HBV also have found tattooing was risk factor detected with a high frequency [25]. But Komas et al. [37] described that tattooing or body piercing did not increase the risk. This difference might be due to the different ethnic study population. In our study, all the subjects were female, which may be biased, as females were more likely to pierce than men. Having a

Table 1 Seroprevalence of HBsAg with socio-demographic characteristics of the study participants

\begin{tabular}{|c|c|c|c|c|c|c|c|}
\hline \multirow{2}{*}{$\begin{array}{l}\text { Characteristic } \\
\text { Age (y) }\end{array}$} & \multirow[t]{2}{*}{ Samples size $(n)$} & \multirow[t]{2}{*}{ Percent (\%) } & \multirow[t]{2}{*}{ HBsAg positive ( $n$ ) } & \multicolumn{2}{|c|}{ Seroprevalence $(\%, 95 \% \mathrm{Cl})$} & \multirow[t]{2}{*}{$x^{2}$} & \multirow[t]{2}{*}{$p$} \\
\hline & & & & & & & \\
\hline $15-19$ & 876 & 7.07 & 75 & 8.57 & $(6.71-10.42)$ & 22.340 & 0.001 \\
\hline $20-24$ & 1353 & 10.92 & 140 & 10.32 & $(8.70-11.94)$ & & \\
\hline $25-29$ & 1783 & 14.39 & 187 & 10.51 & $(9.09-11.93)$ & & \\
\hline $30-34$ & 1754 & 14.15 & 199 & 11.37 & $(9.88-12.86)$ & & \\
\hline $35-39$ & 2174 & 17.54 & 206 & 9.48 & $(8.25-10.71)$ & & \\
\hline $40-44$ & 2408 & 19.43 & 222 & 9.21 & $(8.06-10.37)$ & & \\
\hline $45-49$ & 2045 & 16.50 & 150 & 7.35 & $(6.23-8.48)$ & & \\
\hline \multicolumn{8}{|l|}{ Ethnic group } \\
\hline Han & 6831 & 55.12 & 620 & 9.08 & $(8.40-9.76)$ & 9.636 & 0.001 \\
\hline $\mathrm{Li}$ & 4395 & 35.46 & 464 & 10.56 & $(9.65-11.47)$ & & \\
\hline Others & 1167 & 9.42 & 95 & 8.14 & $(6.57-9.71)$ & & \\
\hline \multicolumn{8}{|l|}{ Marital status } \\
\hline Single & 4219 & 34.04 & 382 & 9.05 & $(8.18-9.92)$ & 1.867 & 0.393 \\
\hline Married & 7257 & 58.56 & 703 & 9.68 & $(9.00-10.36)$ & & \\
\hline Divorced/Widowed & 917 & 7.40 & 94 & 10.25 & $(8.29-12.21)$ & & \\
\hline \multicolumn{8}{|l|}{ Education level } \\
\hline Illiteracy & 2813 & 22.70 & 309 & 10.98 & $(9.82-12.14)$ & 14.442 & 0.002 \\
\hline Junior high & 4421 & 35.67 & 427 & 9.66 & $(8.79-10.53)$ & & \\
\hline Senior high & 3754 & 30.29 & 336 & 8.95 & $(8.04-9.86)$ & & \\
\hline College or higher & 1405 & 11.34 & 107 & 7.62 & $(6.23-9.01)$ & & \\
\hline \multicolumn{8}{|l|}{ Employment } \\
\hline Housekeeper & 7314 & 59.02 & 737 & 10.08 & $(9.39-10.77)$ & 6.574 & 0.010 \\
\hline Employee & 5079 & 40.98 & 442 & 8.7 & $(7.92-9.48)$ & & \\
\hline \multicolumn{8}{|c|}{ Family monthly income (RMB) } \\
\hline$<1000$ & 3931 & 31.72 & 411 & 10.46 & $(9.50-11.42)$ & 10.816 & 0.013 \\
\hline $1000 \sim 2000$ & 4897 & 39.51 & 473 & 9.66 & (8.83-10.49) & & \\
\hline $2000 \sim 5000$ & 2660 & 21.46 & 216 & 8.12 & (7.08-9.16) & & \\
\hline$\geq 5000$ & 905 & 7.30 & 79 & 8.73 & $(6.89-10.57)$ & & \\
\hline \multicolumn{8}{|l|}{ Nulliparous woman } \\
\hline No & 5120 & 41.31 & 623 & 12.17 & $(11.27-13.07)$ & 71.415 & $<0.001$ \\
\hline Yes & 7273 & 58.69 & 556 & 10.86 & $(10.14-11.58)$ & & \\
\hline \multicolumn{8}{|l|}{ Location } \\
\hline East of Hainan & 4012 & 32.37 & 336 & 8.37 & $(7.51-9.23)$ & 9.010 & 0.011 \\
\hline Middle of Hainan & 4123 & 33.27 & 411 & 9.97 & (9.06-10.88) & & \\
\hline West of Hainan & 4258 & 34.36 & 432 & 10.15 & $(9.24-11.06)$ & & \\
\hline Total & 12393 & 100.00 & 1179 & 9.51 & $(8.99-10.02)$ & & \\
\hline
\end{tabular}


Table 2 Possible risk factors for HBsAg seroprevalence in rural women of childbearing age

\begin{tabular}{|c|c|c|c|c|c|}
\hline Variables & Percentage of total subjects, $\%$ & HBsAg Seroprevalence, \% & OR & $95 \% \mathrm{Cl}$ for OR & $p$ \\
\hline \multicolumn{6}{|l|}{ Education level } \\
\hline Junior high or lower & 58.37 & 10.17 & 1.206 & $1.066-1.365$ & 0.003 \\
\hline Senior high or higher & 41.63 & 8.59 & 1.000 & & \\
\hline \multicolumn{6}{|c|}{ Family monthly income (RMB) } \\
\hline$<2000$ & 71.23 & 10.01 & 1.233 & $1.075-1.416$ & 0.003 \\
\hline$\geq 2000$ & 28.77 & 8.27 & 1.000 & & \\
\hline \multicolumn{6}{|c|}{ Have an HBsAg-positive family member } \\
\hline Yes & 14.61 & 11.10 & 1.300 & $1.102-1.535$ & 0.002 \\
\hline No & 64.30 & 8.76 & 1.000 & & \\
\hline Unknown & 21.09 & 10.71 & 1.250 & $1.080-1.447$ & 0.003 \\
\hline \multicolumn{6}{|l|}{ Immunization history } \\
\hline Yes & 39.10 & 8.40 & 1.000 & & \\
\hline No & 61.90 & 10.23 & 1.243 & $1.096-1.410$ & 0.001 \\
\hline \multicolumn{6}{|l|}{ Tattooing } \\
\hline Yes & 13.12 & 10.89 & 1.190 & $1.005-1.410$ & 0.043 \\
\hline No & 86.88 & 9.31 & 1.000 & & \\
\hline \multicolumn{6}{|l|}{ Body piercing } \\
\hline Yes & 77.33 & 9.99 & 1.293 & $1.110-1.506$ & 0.001 \\
\hline No & 22.67 & 7.90 & 1.000 & & \\
\hline \multicolumn{6}{|l|}{ History of dental surgery } \\
\hline Yes & 21.34 & 10.28 & 1.117 & $0.969-1.289$ & 0.128 \\
\hline No & 78.66 & 9.30 & 1.000 & & \\
\hline \multicolumn{6}{|l|}{ History of surgery } \\
\hline Yes & 34.03 & 9.89 & 1.068 & $0.942-1.211$ & 0.307 \\
\hline No & 65.97 & 9.32 & 1.000 & & \\
\hline \multicolumn{6}{|l|}{ Transfusion history } \\
\hline Yes & 8.75 & 11.07 & 1.205 & $0.986-1.472$ & 0.067 \\
\hline No & 91.25 & 9.36 & 1.000 & & \\
\hline \multicolumn{6}{|l|}{ Vaginoscope history } \\
\hline Yes & 18.32 & 10.22 & 1.103 & $1.110-1.506$ & 0.001 \\
\hline No & 81.68 & 9.36 & 1.000 & & \\
\hline \multicolumn{6}{|l|}{ Endoscopy history ${ }^{a}$} \\
\hline Yes & 12.92 & 10.12 & 1.082 & $0.909-1.289$ & 0.376 \\
\hline No & 87.08 & 9.42 & 1.000 & & \\
\hline \multicolumn{6}{|l|}{ Induced abortion history } \\
\hline Yes & 37.53 & 10.23 & 1.142 & $1.010-1.290$ & 0.034 \\
\hline No & 62.47 & 9.08 & 1.000 & & \\
\hline
\end{tabular}

${ }^{a}$ not including vaginoscopy history.

vaginoscopy history and a history of induced abortion among women of childbearing age were two critical risk factors for HBsAg positivity which were different from other population. The prevalence of HBsAg among women with a history of vaginoscopy and induced abortion was significantly higher than those without. We do not know whether this results from confounding bias or other reasons, since there are no related studies to support these findings. However, this illustrates the need to pay seriously attention to promote safe sex behaviours among women of childbearing age to maintain good health of the reproductive system.

In this study, marital status was not a related factor to $\mathrm{HBsAg}$, although some studies have shown marriage and 
heterosexual relationship to be related to HBsAg positivity [12,38]. In a study by Roman et al. [25] in Mexico illuminated that marital status had denoted an OR of 1.92 in single or divorced pregnant women and 7.4 in widows among general population. These differences are probably due to cultural differences in each population. Like many other studies [12,24,37,39], this study showed that a history of blood transfusion, surgery, dental surgery and endoscopy was not a risk factor for HBsAg. Although a study by Zali et al. [35] reported that a history of major surgery was associated to HBV. This probably indicates that there is a good surgery and nursing care environment in Hainan.

This study had three limitations. First, our study was a cross sectional design which was therefore, difficult to establish causal relations. Nevertheless, the findings provide important demographic insights on HBsAg positivity among rural women of childbearing age in Hainan province. Another limitation is that HBV infection can be transmitted efficiently through sexual intercourse and the role of sexual behavior in HBsAg seropositivity was not assessed. Thirdly, this study did not include urban women, who happen to have different economic levels, living surroundings, medical environment and conditions and etcetera from rural population which has impact on HBsAg seroprevalence. Therefore, we plan to conduct a sero-epidemiological survey of urban women in Hainan in the future.

\section{Conclusion}

HBsAg seropositivity among women of childbearing age is a threat not only to their health but the next generation who are at risk of HBV vertical transmission. The prevalence rate of HBsAg among women of childbearing age plays a very important role in the spread of HBV. This study shows that the overall HBsAg seroprevalence among rural women of childbearing age in Hainan was $9.51 \%$, which was high. So efforts should be made to control and prevent the HBV infection among childbearing age women in Hainan with focus on the reported risk factors. Vaccination program should be implemented not only in infants and children but also in adults. Further, the routine maternal HBsAg screening should be promoted and strengthened, especially in rural areas, to the benefit of taking appropriate and effective interventions to prevent mother-to-child transmission of HBV.

\section{Methods}

\section{Study setting and population}

The present study is a cross-sectional, population-based study, carried out from November 2007 to December 2008 in Hainan province, an area which is encircled by the sea, located in the southernmost part of China. It is the youngest province and biggest special economic zone in China. Hainan has a female population of 4.284 million, and $27.08 \%$ (1.160 million) of them are rural women of childbearing age [34]. This survey covered all 18 counties and cities in Hainan. The 18 counties and cities were divided into three regions according to geographical location (i.e. the east, centre and the west). According to the Hainan Provincial Bureau of Statistics that the economic level of the eastern part of Hainan has the best economic development as compared to the west and central regions [34].

Healthy rural women aged 15 to 49 years who were permanent residents of Hainan were eligible for enrollment in the study. The study population was obtained from the list of native residents using a multistage stratified cluster sampling method. The first step was to stratify, all the cities and counties were stratified into three levels according to economic status and then two sites were randomly selected from each economic level. Using this selection method, six towns were selected from each city and county, and a total of 108 towns of Hainan were selected. Thereafter, we randomly selected three villages from each town and we ended up selecting 324 villages. We selected 30 percentage of women aged 15 to 49 years in each village. A total of 12393 rural women of childbearing age were randomly selected and invited to participate in this survey.

\section{Samples and data collection}

A questionnaire which included age, ethnic group, education level, marital status, employment status, family monthly income, history of dental surgery, transfusion history, immunization history, endoscopy, tattooing and some other possible risk factors was completed by each participant before collecting the blood samples. Then $5 \mathrm{ml}$ venous blood samples were obtained from each participant. All fresh serum samples were tested for the presence of HBsAg, using qualitative enzyme-linked immunosorbent assay (ELISA) kits (Yingkechuangxin Company, Xiamen, China). Other markers were not tested. The test was carried out and interpreted according to the manufacturer's instructions.

\section{Statistical analysis}

The database was constructed with Epidata 3.1. Statistical analysis were performed with SPSS 13.0 software for Windows (SPSS Inc., Chicago. IL). Proportions, ratios, and median were applied to describe the sociodemographic characteristics of participants and infection status of HBsAg. Chi-square test was used to identify independent risk factors associated with positive test of HBsAg infection, odds ratios (ORs) and their 95\% CIs were also calculated. The level of statistical significance was set at $P \leq 0.05$. 


\section{Ethical approval}

The study was approved by the Ethics Committee of the Medical Association of Tongji Medical College of Huazhong University of Science and Technology. A written informed consent form was obtained from each study participant before blood sample and data collection.

\section{Abbreviations}

HBV: Hepatitis B virus; HBsAg: Hepatitis B surface antigen;

HCC: Hepatocellular carcinoma; Cl: Confidence interval; OR: Odds ratio.

\section{Competing interests}

The authors declare that they have no competing interests.

\section{Authors' contributions}

YZ and WMF performed the statistical analysis and prepared the manuscript. YKD and LCF participated in the design and coordination of the study and revised the manuscript. XHG, WMH and YG collected the data and help to draft the manuscript. All authors read and approved the final manuscript.

\section{Acknowledgements}

This work was supported by Grants from a NGO called Li Kashing Foundation. We gratefully acknowledge the support from all the team members, local doctors and nurses of 108 township hospitals of 18 counties and cities in Hainan. We appreciated all the rural women of childbearing age in this study for their participation. We also thank Fatch W. Kalembo for his efforts of editing and revising the manuscript.

\section{Author details}

${ }^{1}$ Department of Maternal and Child Health, School of Public Health, Tongji Medical College, Huazhong University of Science and Technology, 13th Hangkong Road, Wuhan, P.R, China. ${ }^{2}$ Department of Prevention and Health Care, Hainan Maternal and Child Health Care Hospital, Haikou, China.

Received: 29 April 2012 Accepted: 27 December 2012

Published: 18 January 2013

\section{References}

1. Andre F: Hepatitis B epidemiology in Asia, the Middle East and Africa. Vaccine 2000, 18(Suppl1):20-22.

2. Alter MJ: Epidemiology of hepatitis B in Europe and worldwide. $J$ Hepatol 2003, 39(Suppl 1):S64-S69.

3. Kao J, Chen D: Global control of hepatitis B virus infection. Lancet Infect Dis 2002, 7:395-403.

4. Yuen M, Lai C: Natural history of chronic hepatitis B virus infection. J Gastroenterol Hepatol 2000, 15:E20-E24.

5. Jane N, Zuckerman M, Zuckerman AJ: The Epidemiology of Hepatitis B. Clin Liver Dis 1999, 2:179-187.

6. Mahamat A, Louvel D, Vaz T, Demar M, Nacher M, Djossou F: Short Report High Prevalence of HBsAg during Pregnancy in Asian Communities at Cayenne Hospital, French Guiana. Am J Trop Med Hyg 2010, 83:711-713.

7. Xia G, Liu C, Cao H, Bi S, Zhan M, Su C, Nan J, Qi X: Prevalence of hepatitis $B$ and $C$ virus infections in the general Chinese population.Results from a nationwide cross-sectional seroepidemologic study of hepatitis $A, B, C$, D, and E virus infections in China, 1992. Int Hepatol Commun 1996, 5:62-73.

8. Kumar A, Pant S, Narang S: Significance of alanine aminotransferase testing in diagnosis of acute and chronic HBV infection. Asian Pac $J$ Cancer Prev 2009, 10:1171-1172.

9. Yao JL: Perinatal transmission of hepatitis B virus infection and vaccination in China. Gut 1996, 38(Suppl 2):S37-S78.

10. Cacciola I, Cerenzia G, Pollicino T, Squadrito G, Castellaneta S, Zanetti AR, Mieli-Vergani G, Raimondo G: Genomic heterogeneity of hepatitis B virus (HBV) and outcome of perinatal HBV infection. J Hepatol 2002, 36:426-432.

11. Yao GB: Importance of perinatal versus horizontal transmission of hepatitis B virus infection in China. Gut 1996, 382:S39-S42.
12. Ghadir MR, Belbasi M, Heidari A, Jandagh M, Ahmadi I, Habibinejad H, Kabiri A, Ghanooni AH, Iranikhah A, Alavian SM: Distribution and risk factors of hepatitis $B$ virus infection in the general population of central iran. Hepat Mon 2012, 12:112-117.

13. Li X, Zheng Y, Liau A, Cai B, Ye D, Huang F, Sheng X, Ge F, Xuan L, Li S, Li J: Hepatitis $B$ virus infections and risk factors among the general population in Anhui Province, China: an epidemiological study. Bmc Public Health 2012, 12:272.

14. Nagalo MB, Sanou M, Bisseye C, Kabore MI, Nebie YK, Kienou K, Kiba A, Dahourou H, Ouattara S, Zongo JD, Simpore J: Seroprevalence of human immunodeficiency virus, hepatitis $B$ and $C$ viruses and syphilis among blood donors in Koudougou (Burkina Faso) in 2009. Blood Transfus 2011, 9:419-424.

15. Durro V, Qyra S: Trends in prevalence of hepatitis B virus infection among Albanian blood donors, 1999-2009. Virol J 2011, 8:96.

16. Salleras L, Dominguez A, Bruguera M, Plans P, Espunes J, Costa J, Cardenosa $N$, Plasencia A: Seroepidemiology of hepatitis B virus infection in pregnant women in Catalonia (Spain). J Clin Virol 2009, 44:329-332.

17. Zhang S, Li RT, Wang Y, Liu Q, Zhou YH, Hu Y: Seroprevalence of hepatitis $B$ surface antigen among pregnant women in Jiangsu, China, 17 years after introduction of hepatitis B vaccine. Int J Gynaecol Obstet 2010, 109:194-197.

18. Attaullah S, Khan S, Naseemullah, Ayaz S, Khan SN, Ali I, Hoti N, Siraj S: Prevalence of $\mathrm{HBV}$ and $\mathrm{HBV}$ vaccination coverage in health care workers of tertiary hospitals of Peshawar, Pakistan. Virol J 2011, 8:275.

19. Ministry of Health of the People's Republic of China: Sero-epidemiological Investigation of HBV infection in the general Chinese population in 2006. 2008. http://www.moh.gov.cn/publicfiles/business/htmlfiles/mohbgt/s3582/ 200804/33253.htm.

20. Elefsiniotis IS, Glynou I, Pantazis KD, Fotos NV, Magaziotou I, Kada H: Prevalence of chronic HBV infection among 13,581 women at reproductive age in Greece. A prospective single center study. J Clin Virol 2005, 32:179-180.

21. Boisier P, Rabarijaona L, Piollet M, Roux JF, Zeller HG: Hepatitis B virus infection in general population in Madagascar: evidence for different epidemiological patterns in urban and in rural areas. Epidemiol Infect 1996, 117:133-137.

22. Mehmet D, Meliksah E, Serif Y, Gunay S, Tuncer O, Zeynep S: Prevalence of hepatitis $B$ infection in the southeastern region of Turkey: comparison of risk factors for HBV infection in rural and urban areas. Jpn J Infect Dis 2005, 58:15-19.

23. Mohebbi SR, Sanati A, Cheraghipour K, Rostami NM, Shalmani HM, Zali MR: Hepatitis $C$ and hepatitis $B$ virus infection: epidemiology and risk factors in a large cohort of pregnant women in lorestan, west of iran. Hepat Mon 2011, 11:736-739.

24. Murhekar MV, Murhekar KM, Arankalle VA, Sehgal SC: Epidemiology of hepatitis B infection among the Nicobarese-a mongoloid tribe of the Andaman and Nicobar Islands, India. Epidemiol Infect 2002, 128:465-471.

25. Roman S, Panduro A, Aguilar-Gutierrez Y, Maldonado M, Vazquez-VanDyck M, Martinez-Lopez E, Ruiz-Madrigal B, Hernandez-Nazara Z: A low steady HBsAg seroprevalence is associated with a low incidence of HBV-related liver cirrhosis and hepatocellular carcinoma in Mexico: a systematic review. Hepa Inter 2009, 3:343-355.

26. Ranger-Rogez S, Alain S, Denis F: Hepatitis viruses: mother to child transmission. Pathol Biol (Paris) 2002, 50:568-575.

27. Lin L, Lv C, Yan H, Lin J, Ding J, Pan X: Survey of status of HBsAg carriers in child- bearing women in the rural areas of Sanya City. China Trop Med 2001, 1:361-362

28. Liu L, Shen L, Fu M: Survey of Hepatitis B vitus infection and cognition and action in the population of Qionghai City. China J of Modern Med 2008, 18:1873-1876.

29. Fang ZL, Harrison TJ, Yang JY, Chen QY, Wang XY, Mo JJ: Prevalence of hepatitis $B$ virus infection in a highly endemic area of southern China after catch-up immunization. J Med Virol 2012, 84:878-884.

30. Bancroft WH, Snitbhan R, Scott RM, Tingpalapong M, Watson WT, Tanticharoenyos P, Karwacki JJ, Srimarut S: Transmission of hepatitis B virus to gibbons by exposure to human saliva containing hepatitis $B$ surface antigen. J Infect Dis 1977, 135:79-85.

31. Gray Davis L, Weber DJ, Lemon SM: Horizontal transmission of hepatitis B virus. Lancet 1989, 333:889-893. 
32. Akbar N, Basuki B, Mulyanto, Garabrant DH, Sulaiman A, Noer HS: Ethnicity, socioeconomic status, transfusions and risk of hepatitis B and hepatitis $C$ infection. J Gastroen Hepatol 1997, 12:752-757.

33. Wang CS, Chang TT, Chou P: Differences in risk factors for being either a hepatitis B carrier or anti-hepatitis $C+$ in a hepatoma-hyperendemic area in rural Taiwan. J Clin Epidemiol 1998, 51:733-738.

34. Hainan Government: Hainan Yearbook 2011. Hainan, China: 2008. http:// www.hi.stats.gov.cn/tabid/213/Default.aspx). Accessed 22 February 2012.

35. Zali MR, Mohammad K, Farhadi A, Masjedi MR, Zargar A, Nowroozi A: Epidemiology of hepatitis B in the Islamic Republic of Iran. East Mediterr Health J 1996, 2:290-298.

36. Zhang J, Zou S, Giulivi A: Epidemiology of hepatitis B in Canada. Can J Infect Dis 2001, 6:345-350.

37. Komas NP, Bai-Sepou S, Manirakiza A, Leal J, Bere A, Le Faou A: The prevalence of hepatitis B virus markers in a cohort of students in Bangui, Central African Republic. BMC Infectious Disease 2010, 10:226.

38. McQuillan GM, Coleman PJ, Kruszon-Moran D, Moyer LA, Lambert SB, Margolis HS: Prevalence of hepatitis B virus infection in the United States: the National Health and Nutrition Examination Surveys, 1976 through 1994. Am J Public Health 1999, 89:14-18.

39. Eke AC, Eke UA, Okafor Cl, Ezebialu IU, Ogbuagu C: Prevalence, correlates and pattern of hepatitis B surface antigen in a low resource setting. Virol J 2011, 8:12.

doi:10.1186/1743-422X-10-25

Cite this article as: Zhang et al:: Hepatitis B surface antigen prevalence among 12393 rural women of childbearing age in Hainan Province, China: a cross-sectional study. Virology Journal 2013 10:25.

\section{Submit your next manuscript to BioMed Central and take full advantage of:}

- Convenient online submission

- Thorough peer review

- No space constraints or color figure charges

- Immediate publication on acceptance

- Inclusion in PubMed, CAS, Scopus and Google Scholar

- Research which is freely available for redistribution 